\title{
A large wet snow avalanche cycle in West Greenland quantified using remote sensing and in situ observations
}

\author{
Jakob Abermann ${ }^{1,2}$ D $\cdot$ Markus Eckerstorfer ${ }^{3} \cdot$ Eirik Malnes $^{3} \cdot$ Birger Ulf Hansen $^{4}$
}

Received: 19 November 2018 / Accepted: 28 June 2019 / Published online: 4 July 2019

(c) The Author(s) 2019

\begin{abstract}
On 11 April 2016 we observed high slushflow and wet snow avalanche activity at the environmental monitoring station Kobbefjord in W-Greenland. Snow avalanches released as a result of snow wetting induced by rain-on-snow in combination with a strong rise in air temperature. We exploit high-resolution satellite imagery covering pre- and post-event conditions for avalanche quantification and show that nearly 800 avalanches were triggered during this cycle. The nature of this extraordinary event is put into a longer temporal context by analysing several years of meteorological data and time-lapse imagery. We find that no event of similar size has occurred during the past 10 years of intense environmental monitoring in the study area. Meteorological reanalysis data reveal consistent relevant weather patterns for potential rain-on-snow events in the study area being warm fronts from Southwest with orographic lifting processes that triggered heavy precipitation.
\end{abstract}

Keywords Avalanche $\cdot$ Slushflow $\cdot$ Arctic $\cdot$ Ecosystem effect $\cdot$ Remote sensing

\section{Introduction}

Wet snow avalanches are a common type of snow avalanche (hereafter also called avalanche) and can release from a point or as a slab, in both cases transporting high-density snow masses downslope at relatively low flow velocities (McClung and Schaerer 2006). Wet snow avalanches are serious natural hazards, due to their mass, their long runout distances and their difficulty to forecast (Bellaire et al. 2017). Slushflows are a specific form of wet snow avalanche and are defined as a 'mudflow-like flowage of water-saturated snow' (Washburn and

Electronic supplementary material The online version of this article (https://doi.org/10.1007/s1106 9-019-03655-8) contains supplementary material, which is available to authorized users.

Jakob Abermann

jakob.abermann@uni-graz.at

1 Department of Geography and Regional Science, University of Graz, Heinrichstraße 36, 8010 Graz, Austria

2 Asiaq, Greenland Survey, Pb 1003, 3900 Nuuk, Greenland

3 Norut, Postboks 6434, 9294 Tromsö, Norway

4 Copenhagen University, Øster Voldgade 10, 1350 Copenhagen, Denmark 
Goldthwait 1958), with a very high liquid water content (Fierz et al. 2009). Slushflows release as result of strength loss within a saturated snowpack or at the interface between snow and ground when a hydraulic pressure gradient builds up from an increasingly inclined meltwater table (Gude and Scherer 1995). The occurrence of permafrost or a frozen bed underneath the snowpack impedes meltwater infiltration in the soil; hence, slushflows are common in the Arctic (Washburn and Goldthwait 1958; Nobles 1966). Their potential of destroying infrastructure is especially high in more densely populated areas of the Arctic such as Norway (Hestnes 1998), Iceland (Decaulne and Sæmundsson 2006) or Alaska (Onesti 1985). Their erosional power and importance in triggering spring river break-up furthermore assign them an ecosystem function (Washburn and Goldthwait 1958). They trigger to a large degree spontaneously with an important physical precondition being an isothermal, saturated snowpack as a result of short and intense energy input periods (Mitterer and Schweizer 2013). The energy input mainly stems from either rain-on-snow events and the associated turbulent heat exchange (Hansen et al. 2014), rapid melting (Hestnes and Bakkehøi 2004), or a combination of the two (Decaulne and Sæmundsson 2006). Warming throughout the twentieth century has intensified in the Arctic (Walsh et al. 2012) and in Greenland (Hanna et al. 2012; Abermann et al. 2017) in general and extreme winter warming events have increased (Vikhamar-Schuler et al. 2016). A projected doubling and up to tripling in the frequency of these winter warming events is expected in the next 50-100 years compared to a 1985-2014 reference period (Vikhamar-Schuler et al. 2016). This Arctic amplification is also projected to result in more frequent and intensified rain-on-snow events (Pedersen et al. 2015; Bintanja and Andry 2017). The majority of impact studies deal with impacts of extreme winter weather events on the ecosystems (Bokhorst et al. 2009; Hansen et al. 2014; Cooper 2014). It is, however, likely that wet snow avalanche activity will also increase in frequency, threatening growing populations and infrastructure as it was pointed out by Eckerstorfer and Christiansen (2011).

Connecting event-based avalanche studies to longer meteorological time series is powerful in order to determine weather conditions that lead to large-scale avalanche events. Similar research has been completed in Sweden (Rapp 1960), Greenland (Nobles 1966), Alaska (Onesti 1985), Spain (Furdada et al. 1999) and Svalbard (Eckerstorfer and Christiansen 2011). Avalanche cycles on a large spatial scale have been reported, mainly in the inhabited areas of the Alps (Höller 2009; Rousselot et al. 2010) or North America (Birkeland and Mock 2001) where compilations of avalanches are based on extensive ground-based reporting. A comprehensive list of global avalanche disasters is compiled in Rudolf-Miklau et al. (2015). In uninhabited areas, these large avalanche cycles often remain unobserved, which is why the potential of high-resolution satellite-borne remote sensing in monitoring avalanche activity over large regions bears potential (Eckerstorfer et al. 2016).

Using these innovative remote sensing tools together with a comprehensive ground-based ecosystem monitoring network and meteorological data enabled us to quantify the extent of a major slushflow and wet snow avalanche event in West Greenland. Our study highlights the importance of multi-variate long-term monitoring in a changing climate in order to collect the relevant in situ data in the case of an extraordinary event and shows the potential of the use of freely and globally available satellite data for environmental monitoring. 


\section{Study area}

Our study focuses on large parts of coastal Southwest Greenland, around the capital Nuuk. The area is characterized by a low-arctic climate with a strong gradient in continentality with the open ocean and the ice sheet as the two end-members. The Greenland Ecosystem Monitoring Programme (www.g-e-m.dk) performs long-term monitoring of ecosystem components since 2007 in Kobbefjord (KF) a small fjord near Nuuk. The area is equipped with an automated meteorological station $(\mathrm{KOB})$, several hydrometric stations and six time-lapse cameras (K1-K6). In addition to GEM stations, we used two meteorological stations from the Asiaq monitoring network (www.asiaq.gl) at Nuuk (NUK) and Kapisillit (KAP). All stations' coordinates are given in Table 1 and their locations shown Fig. 1.

\section{Data and methods}

\subsection{Atmosphere and hydrology}

Atmospheric data are measured at KOB on two separate masts that store data on independent masts with individual power supply in order to minimize data loss. Air temperature and precipitation data as well as snow depth data from KOB are used. For a description of the data and the measured parameters, we refer to the GEM annual reports (e.g. Christensen and Topp-Jorgensen (2018)). Discharge is derived from hourly water level measurements at a hydrometric station at BS_Q. A stage-discharge relation based on 17 manual discharge measurements under different water levels has been used (Iversen and Pernosky 2010). NCEP/NCAR Reanalysis data for $1000 \mathrm{hPa}$ air temperature, $500 \mathrm{hPa}$ geopotential height and surface precipitation (Kalnay et al. 1996) have been used in order to put the results into a larger spatio-temporal context, and access has been gained through http://www.esrl.noaaa .gov/posd/.

In order to compare synoptic conditions of the April 2016 event with other cases where strong rain falls under very warm conditions during snow cover, we study specifically cases

Table 1 Locations of all stations used in this study (UTM WGS84): Nuuk (NUK), Kapisillit (KAP), Kobbefjord climate station $(\mathrm{KOB})$ and the 6 camera stations (K1-K6)

\begin{tabular}{llll}
\hline Station name & Lat & Lon & $\begin{array}{l}\text { Elevation } \\
\text { (m a.s.1. })\end{array}$ \\
\hline NUK & $64^{\circ} 10^{\prime} 46^{\prime \prime}$ & $-51^{\circ} 43^{\prime} 34^{\prime \prime}$ & 82 \\
KAP & $64^{\circ} 25^{\prime} 57^{\prime \prime}$ & $-50^{\circ} 16^{\prime} 18^{\prime \prime}$ & 71 \\
KOB & $64^{\circ} 7^{\prime} 59^{\prime \prime}$ & $-51^{\circ} 20^{\prime} 36^{\prime \prime}$ & 37 \\
K1 & $64^{\circ} 7^{\prime} 27^{\prime \prime}$ & $-51^{\circ} 22^{\prime} 58^{\prime \prime}$ & 295 \\
K2 & $64^{\circ} 7^{\prime} 25^{\prime \prime}$ & $-51^{\circ} 22^{\prime} 54^{\prime \prime}$ & 307 \\
K3 & $64^{\circ} 7^{\prime} 21^{\prime \prime}$ & $-51^{\circ} 22^{\prime} 19^{\prime \prime}$ & 546 \\
K4 & $64^{\circ} 7^{\prime} 22^{\prime \prime}$ & $-51^{\circ} 22^{\prime} 17^{\prime \prime}$ & 533 \\
K5 & $64^{\circ} 9^{\prime} 6^{\prime \prime}$ & $-51^{\circ} 20^{\prime} 47^{\prime \prime}$ & 757 \\
K6 & $64^{\circ} 9^{\prime} 6^{\prime \prime}$ & $-51^{\circ} 20^{\prime} 47^{\prime \prime}$ & 757 \\
BS & $64^{\circ} 7^{\prime} 52^{\prime \prime}$ & $-51^{\circ} 21^{\prime} 27^{\prime \prime}$ & 41 \\
BS_Q & $64^{\circ} 7^{\prime} 58^{\prime \prime}$ & $-51^{\circ} 22^{\prime} 42^{\prime \prime}$ & 41 \\
\hline
\end{tabular}

Lake Badesø (BS) serves as a visual reference in Fig. 2 and the discharge is measured at the hydrometric station BS_Q 


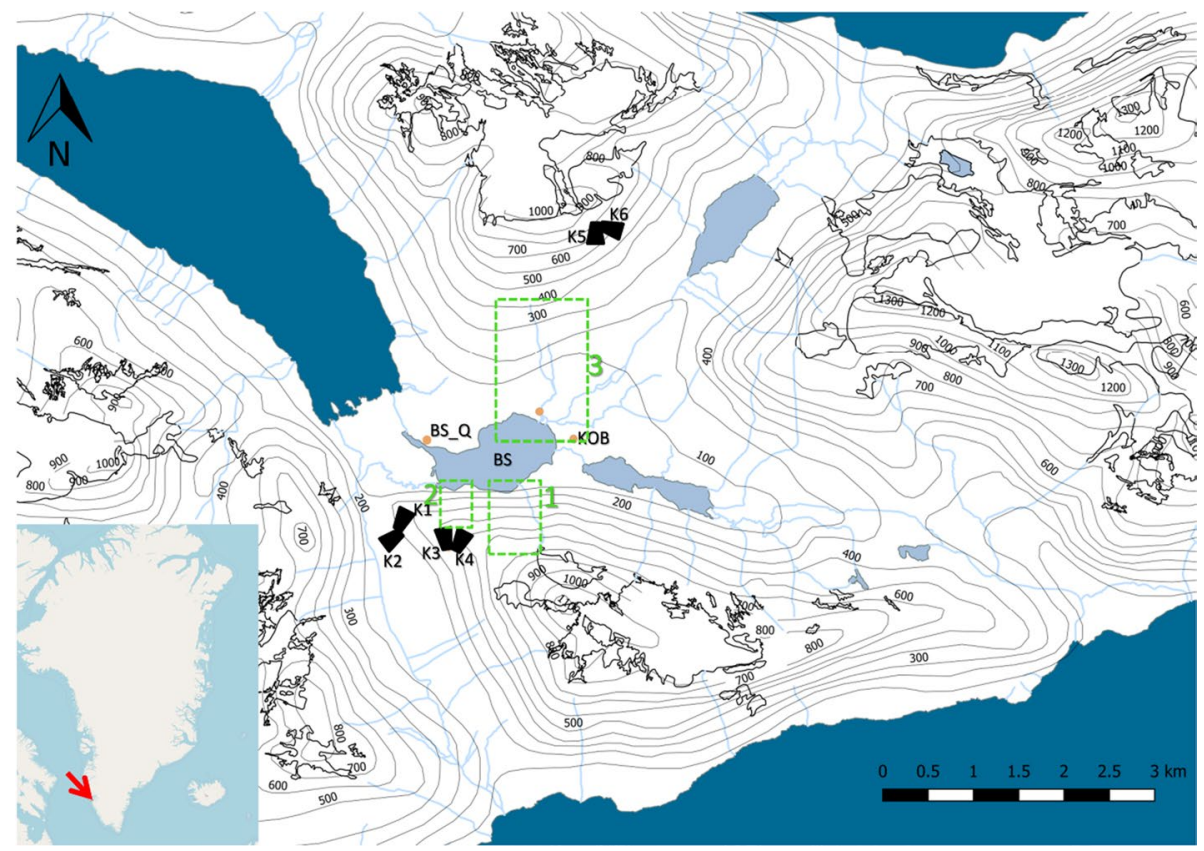

Fig. 1 Map of the Kobbefjord catchment and the camera stations (K1-K6), the station KOB, the hydrometric station BS_Q and lake Badesø (BS). The green rectangles display the extent shown in Fig. 2. Vector data of the map stems from Asiaq, Greenland Survey and the figure was assembled with the open-source software QGIS

with more than $15 \mathrm{~mm} /$ day total precipitation or daily mean air temperature of $9{ }^{\circ} \mathrm{C}$ or higher.

\subsection{Remote sensing}

The European Commission's Copernicus environmental monitoring programme provides free, global satellite data. For avalanche detection, we used radar and optical data from the Sentinel-1 and Sentinel-2 constellation, respectively. Data from both satellite constellations were downloaded from the ESA Sentinel Scientific Data Hub (https://scihub.esa.int/dhus).

The active radar sensors on board of the Sentinel-1 satellites (A \& B) illuminate the Earth's surface and measure the energy that is scattered back to them. In case of an avalanche release, relatively more energy is scattered back from avalanche debris (depositional part of an avalanche) than from undisturbed snow. The high backscatter stems from the relatively high surface roughness that avalanche debris is characteristic for (Wiesmann et al. 2001; Eckerstorfer and Malnes 2015). In case of full-depth avalanches eroding the slide path, increased surface roughness from the rocky ground, vegetation or sediments is also detectable.

Interpretation of the radar images and manual delineation of avalanche debris are facilitated by a temporal change detection method (Lu et al. 2004). These change detection images are constructed from two single radar backscatter images of similar satellite orbit, showing the change in backscatter over time. As avalanche debris exhibit 


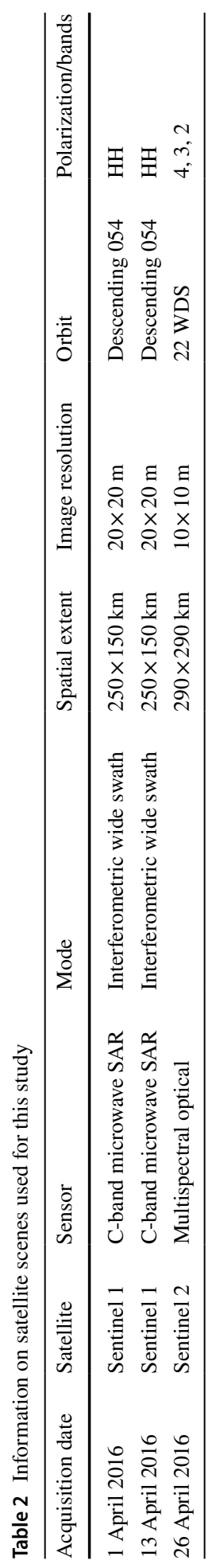


relatively high backscatter, their occurrence in the latter backscatter image makes them detectable. Due to the sharp backscatter contrast between avalanche debris and undisturbed snow in the surrounding, manual outlining becomes possible (Eckerstorfer et al. 2017).

To quantify the magnitude and spatial extent of the wet snow avalanche cycle, we downloaded Sentinel-1 images from 1 and 13 April 2016; for details on the scenes used for this study see Table 2. From these two single radar backscatter images, we constructed a change detection image showing all avalanche activity within a 12-day period. For improved identification and manual delineation of avalanche debris, we coloured relative backscatter change, both increase and decrease, by putting the 1 April image into the red [R] and blue [B] channels and the 13 April 2016 image into the green [G] channel of an RGB image composite (RGBIC from hereafter, Fig. 2a). Avalanche debris appeared in green while wet snow, exhibiting a decrease in backscatter appeared in pink (Nagler and Rott 2000). This strong contrast allowed for interpretation and delineation of avalanche debris in ArcGIS 10.

A cloud-free Sentinel-2 image from 26 April 2016 was used for avalanche detection in an optical satellite image. We constructed a contrast stretched RGB image for the visual channels 4, 3 and 2, corresponding to red, green, and blue channels. Detection of avalanches in optical imagery is relatively straightforward, given the image is uniformly exposed (Lato et al. 2012; Larsen et al. 2013). In this case, avalanches were detectable by their brown signature, due to being full-depth avalanches with erosional effects (Figs. 2b, 3, 4).

A qualitative in situ evaluation has been performed comparing the remote sensing results with ground-based time-lapse imagery (Figs. 2c, 3). All satellite images were processed (geocoding and topographic correction of the radar images) with the software GSAR (Larsen et al. 2005).
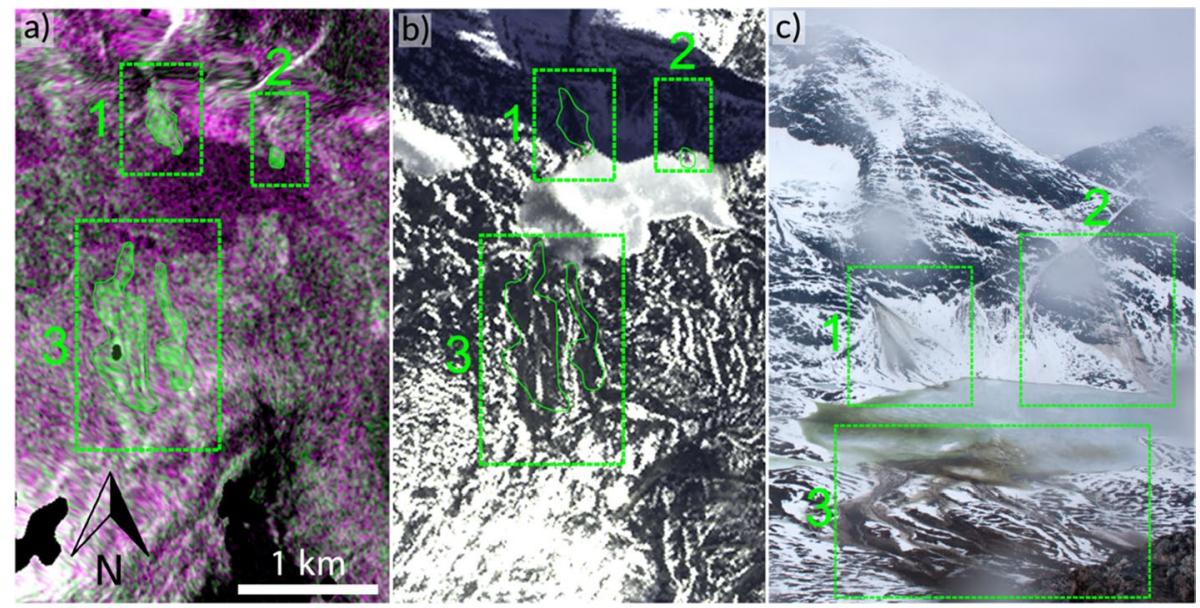

Fig. 2 Avalanche delineation and in situ observations: Comparison of a Sentinel-1 RGBIC activity map, b Sentinel-2 visible scene of the same extent as (a) and a c ground-based photograph from the time-lapse camera system K5 run by B. Hansen. Three individual avalanches are depicted in rectangles 1, 2 and 3. The figure was assembled in Adobe Photoshop CC (https://www.adobe.com/no/products/photoshop.html) 

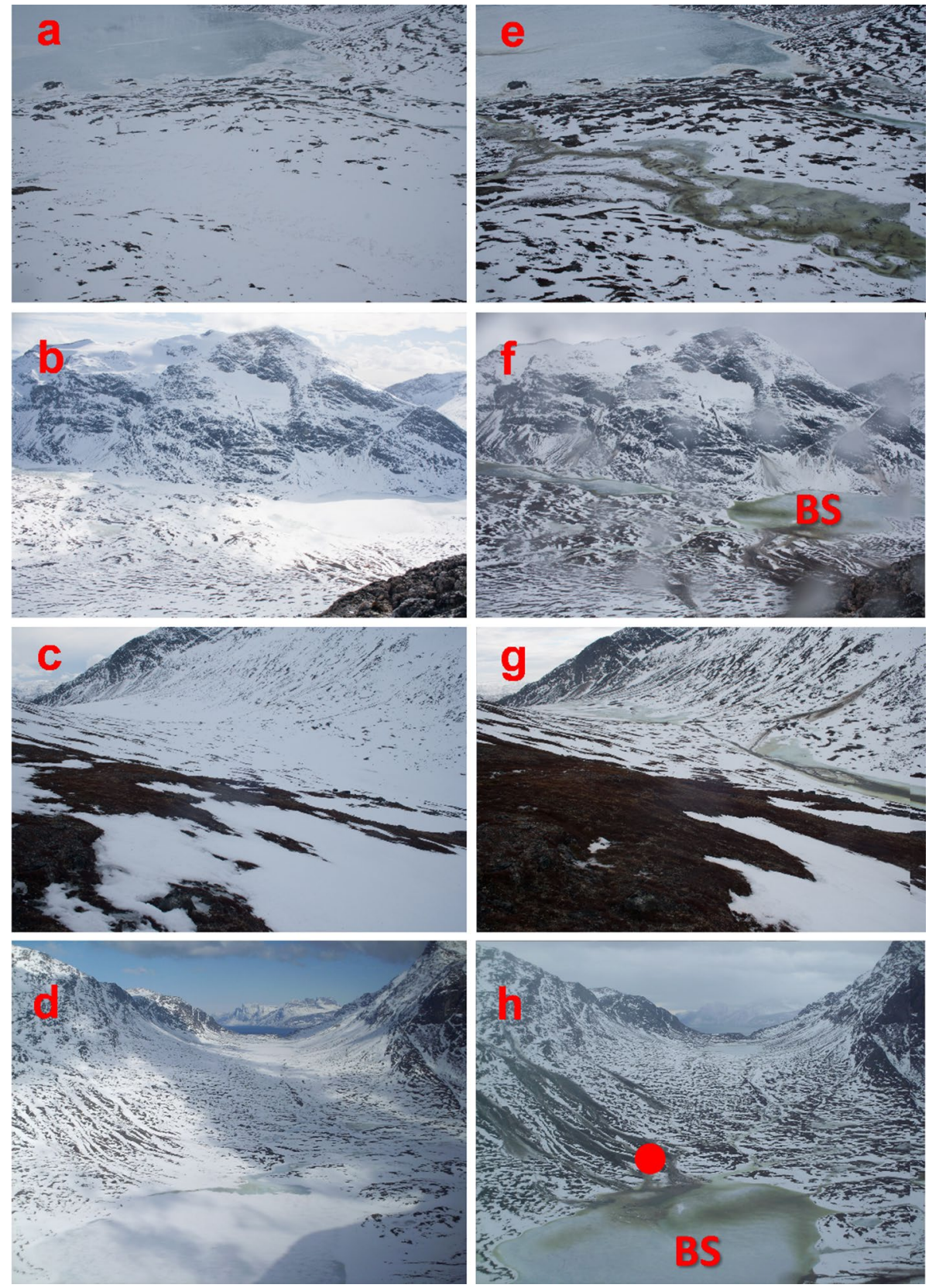

Fig. 3 Photographic evidence: Photos from time-lapse cameras K3 (a, e), K5 (b, f), K2 (c, g) and K4 (d, h) showing the landscape before (a-d) and after $(\mathbf{e}-\mathbf{h})$ the avalanche event. Lake Bades $\emptyset$ (BS) is marked in $\mathrm{f}$ and $\mathrm{h}$. The red dot in $\mathrm{h}$ indicates where the close-up pictures of Fig. 3 are taken. The time-lapse systems are run by B. Hansen 
Fig. 4 Field evidence: Close-ups of the transported debris taken during the field visit on April 162016 by J. Abermann at the approximate location of the red dot in Fig. $2 \mathrm{~h}$
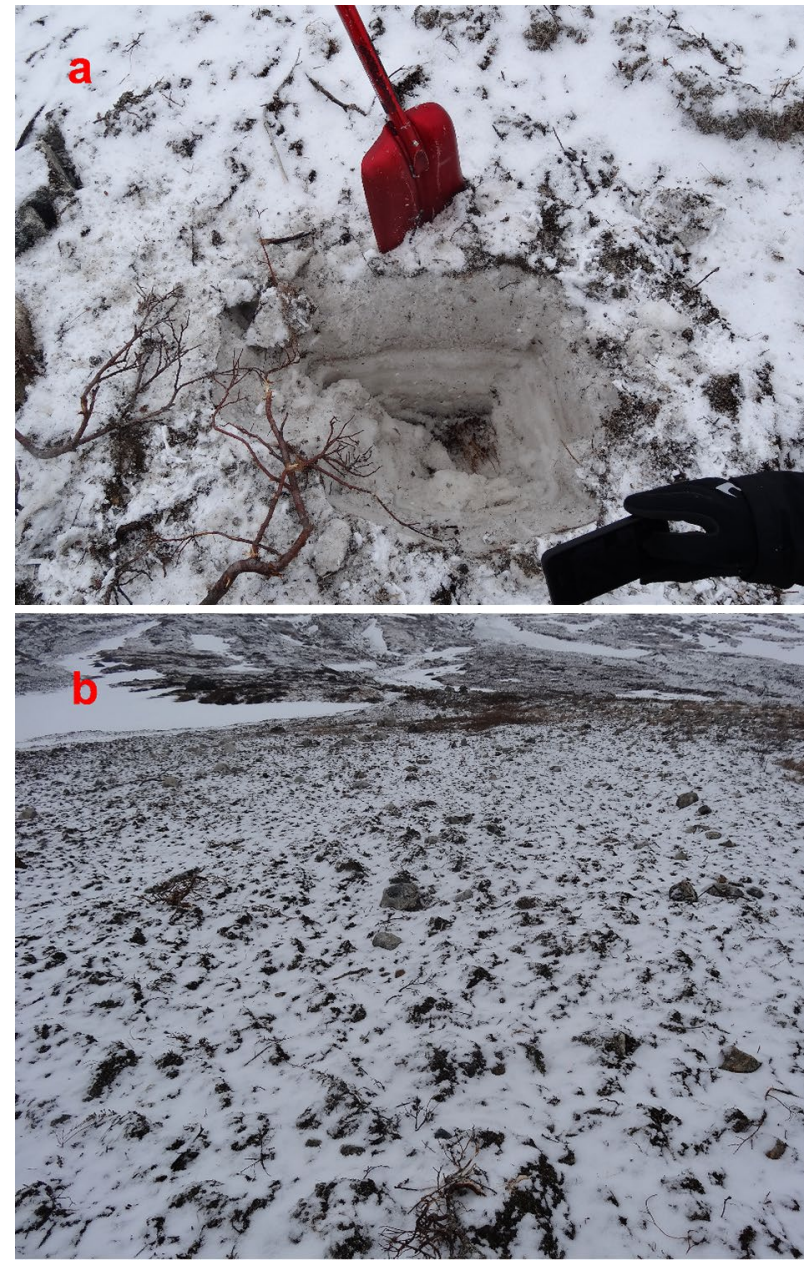

\section{Results}

\subsection{Weather conditions}

A pressure ridge built up on 9 April, aligning and intensifying along the southeast coast of Greenland by 10 April 2016. While a high pressure system decoupled on April 11 with its center just off Greenland's Southeast coast, a trough formed whose embedded cold front collided with the warm front associated with the high pressure system. This synoptic condition has earlier been identified to carry the potential to trigger rapid spring warming events (Rogers et al. 1997). Southwest Greenland remained in the warm sector of the system and was impacted by a strong warm front (Fig. S2). The collision of air masses, the landmass as a natural obstacle and the moisture source of the Atlantic Ocean all favoured high precipitation rates (see Fig. S4 for overview on the synoptic conditions). Pronounced warming from -4.0 to $18.2{ }^{\circ} \mathrm{C}\left(\Delta \mathrm{T}: 22.2{ }^{\circ} \mathrm{C}\right)$ together with heavy precipitation $(\Sigma \mathrm{P}: 25 \mathrm{~mm})$ occurred between 9 and 11 April 2016 at KOB (Fig. 5). A gradient in continentality was 


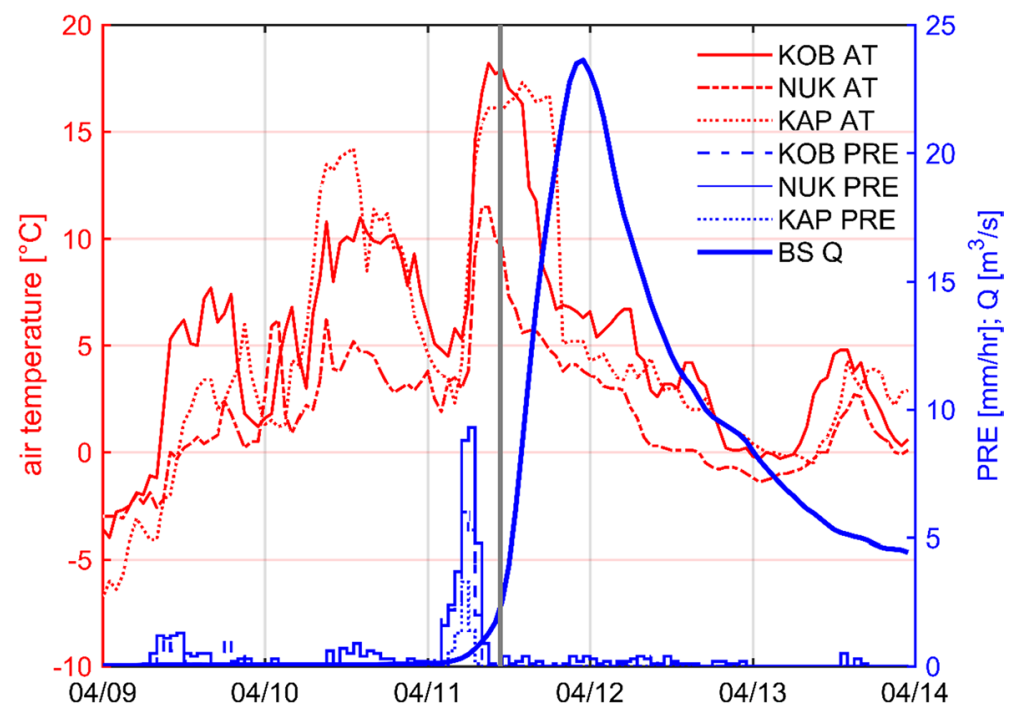

Fig. 5 Meteorological conditions: The meteorological condition prior to, during and after the avalanche event with hourly averages of air temperature ( $\mathrm{red},{ }^{\circ} \mathrm{C}$ ) and precipitation rates (blue, $\mathrm{mm} / \mathrm{h}$ ) at the stations Nuuk (NUU), Kobbefjord (KF) and Kapisillit (KAP). Discharge Q (blue, solid, $\mathrm{m}^{3} / \mathrm{s}$ ) from lake Bades $\emptyset$, the lake draining the KF basin is given on the right axis. The grey line indicates the timing of the avalanche that destroyed an automated station in KF (11 April 2016 10:45)

observed for the same period with a weaker air temperature rise $\left(\Delta \mathrm{T}: 14.6{ }^{\circ} \mathrm{C}\right)$ but higher precipitation ( $\Sigma \mathrm{P}: 49 \mathrm{~mm}$ ) in more maritime Nuuk (NUK) and an even stronger warming $\left(\Delta \mathrm{T}: 24.1^{\circ} \mathrm{C}\right)$ but less precipitation $(\Sigma \mathrm{P}: 7 \mathrm{~mm})$ in more continental Kapisillit (KAP). The bulk of precipitation happened early on 11 April, before and during the rapid warming. Most precipitation fell in Southwest Greenland just south of Nuuk (Fig. S4). Wind remained moderate during the event, rarely exceeding $10 \mathrm{~m} / \mathrm{s}$ in $10 \mathrm{~min}$ averages (Fig. S3). We know that most avalanches released between 10 April noon and 11 April noon as this is evident from the daily time-lapse images available in the region (Fig. 3). One automated station was destroyed by an avalanche on 11 April at ca. 10:45 AM. This coincides temporally with the highest temperatures and occurred after the most intense precipitation. Discharge rose from very low winter values $\left(<0.5 \mathrm{~m}^{3} / \mathrm{s}\right)$ to $23 \mathrm{~m}^{3} / \mathrm{s}$ with a time lag of approx. $12 \mathrm{~h}$ from peak precipitation to peak discharge (Fig. 5).

\subsection{Synoptic-scale avalanche activity}

The RGBIC showing avalanche activity in the period 1-13 April 2016 has an overall purple tone, which indicates that within the 12 days, snow conditions transformed from dry to wet (Fig. 6a). The surface roughness change stemming from avalanche debris and downto-the-ground eroded slide paths (see Fig. 3 and S1 for time-lapse imagery that served for in situ evaluation) led to localized, relative backscatter increase, visualized with green colour in Fig. 6a. Based on these favourable conditions for avalanche detection, a total of 682 avalanches were quantified in the RGBIC (Fig. 6a, green markers).

In the Sentinel-2 image from 26 April 2016, a total of 281 features were detectable, of which 182 were already detected in the RGBIC from 01 April 2018 and 13 


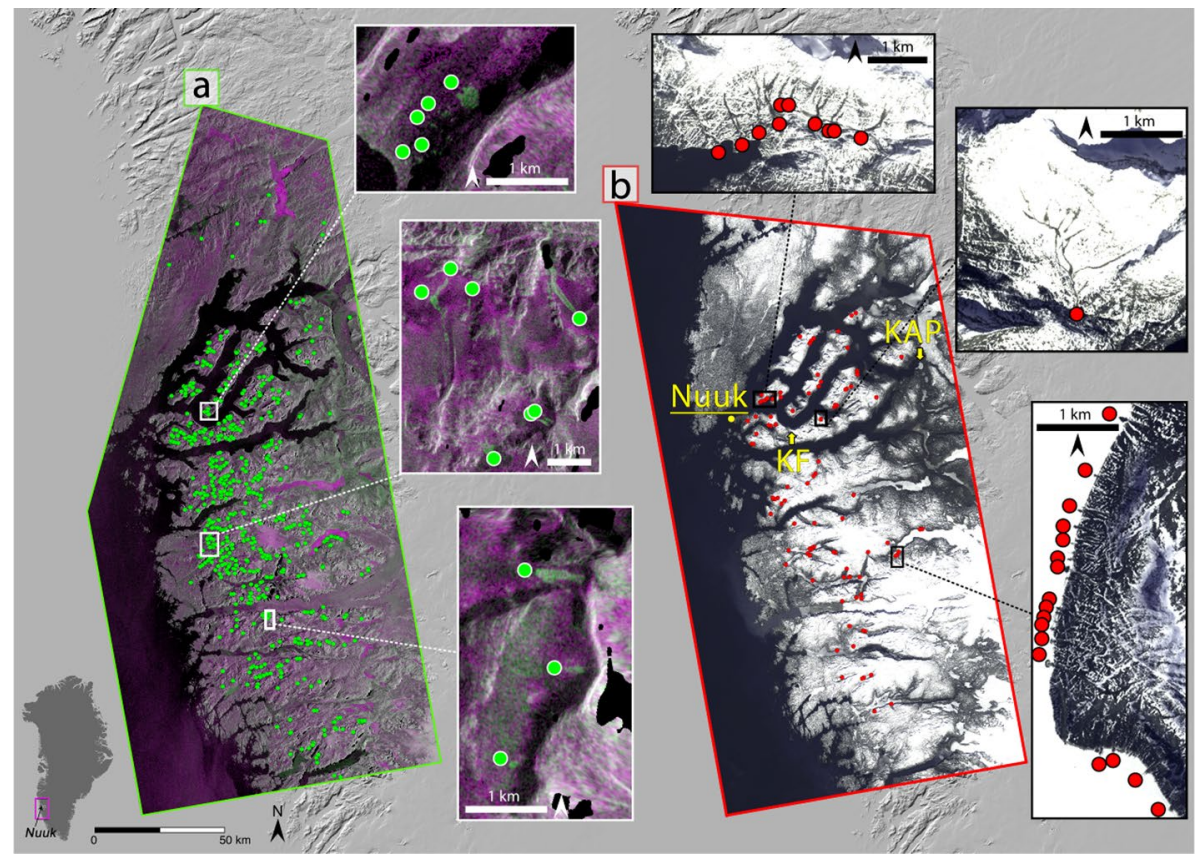

Fig. 6 Avalanche occurrence: a Ground swath of the Sentinel-1 RGBIC from 13 April 2016. b Ground swath of the Sentinel-2 RGB image from 26 April 2016. Avalanche detections are marked at their furthest runout distance with green and red dots respectively. Rectangles show examples of avalanche activity. We used ArcGIS 10.1 (https://www.arcgis.com/features/index.html) to produce the maps in Fig. 5 by overlaying the Sentinel-1 and Sentinel-2 images onto a hillshade. The hillshade was produced using the GIMP DEM (https://bpcrc.osu.edu/gdg/data/gimpdem). The figure was assembled in Adobe Photoshop CC (https ://www.adobe.com/no/products/photoshop.html)

April 2018. This results in a total of 781 unique avalanches that can be assigned to the avalanche cycle presented. The spatial extent of the avalanche cycle shows avalanches occurring mainly in the more mountainous and more maritime western part of the area, while hardly any avalanches have been detected in the flatter and drier eastern part. A large latitudinal spread of activity with over $150 \mathrm{~km}$ confirms the large-scale nature of this event (Fig. 6).

A qualitative assessment of the shape of the avalanches suggests that the majority of detections in the RGBIC were wet slab avalanches with their distinct tongue-shaped form (examples given in insets of Fig. 6a). The majority of detections in the Sentinel-2 image, however, were full-depth slushflows, breaking up drainages and creeks (examples in insets of Fig. 6b) partly containing vegetation and sediments (see Fig. 4 for field evidence). This assessment is supported by the statistical analysis of the avalanche topography and morphology presented in Fig. 7. Gently inclined runouts, which are more prevalent in avalanches detected in the Sentinel-2 image, are typical of wet snow avalanches and especially slushflows. These slushflows also stopped mostly at elevations around sea level compared to the avalanches detected in the RGBIC. Detections from both sensors had prevailing southeasterly aspects with the Sentinel-2 detections being larger in area. The larger size can be expected from slushflows where the entire slide path was detectable. 

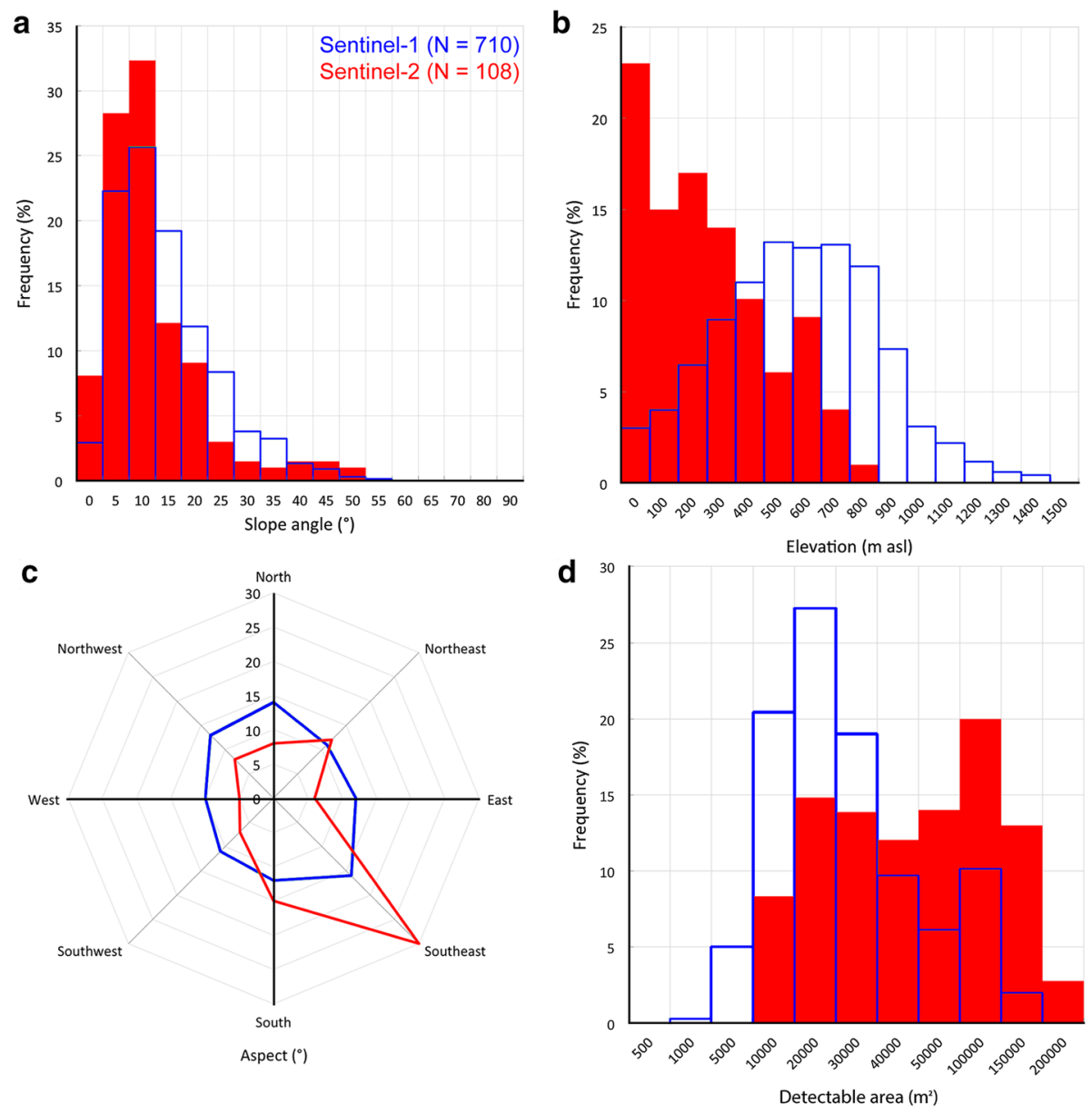

Fig. 7 Avalanche statistics: Summary statistics of topographical and morphological parameters from the furthest runout point of all avalanches detected in the Sentinel-1 (green) and Sentinel-2 (red) images: a slope angle, $\mathbf{b}$ elevation, $\mathbf{c}$ aspect and $\mathbf{d}$ size distribution

\subsection{Extreme event}

Considering the detected large-scale avalanche activity, a relevant question is how unusual is such an event? We made use of a 10-year time series of selected automated time-lapse imagery in the KF basin and found no comparable event where such intense avalanche activity had taken place. We deem this event thus very likely unique in the observation period (2007-2016). Daily compilations of available imagery are shown in videos in S2. In order to highlight what the triggering conditions of such an extreme event may have been, we show several relevant meteorological parameters for days with significant snow cover (i.e. snow depth $>0.15 \mathrm{~m}$; Fig. 8). We found that the April 2016 event has been the one with the highest positive mean air temperatures (x-axis), while total daily precipitation (y-axis) ranks only number 10 (Fig. 8). Daily mean air 


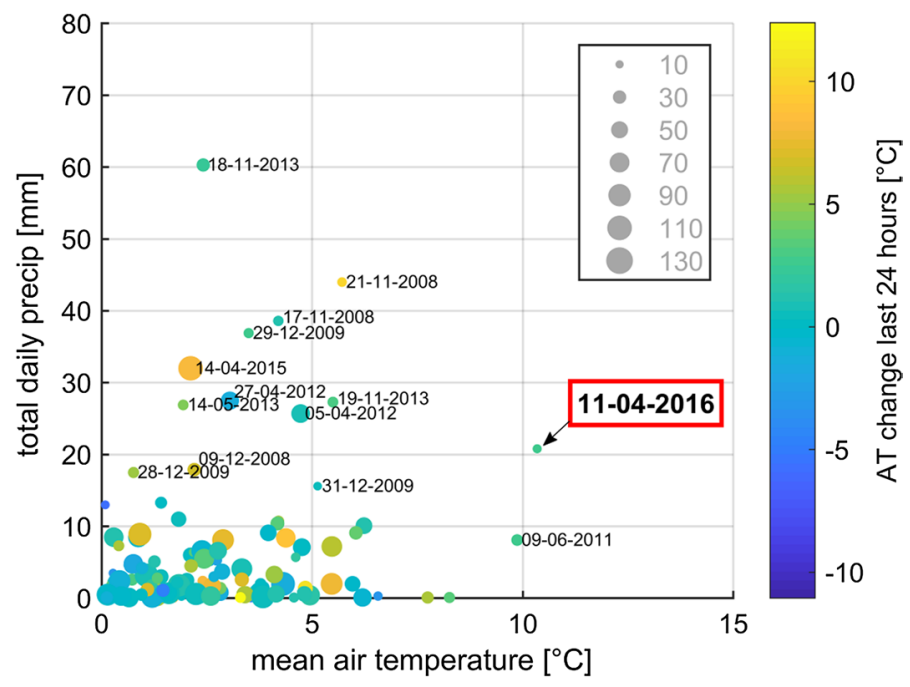

Fig. 8 Atmospheric drivers: Mean air temperature vs total daily precipitation for all cases relevant for a wet snow avalanche event between 2007 and 2016. Circle-size is proportional to snow depth (SD) during the event, while the colour code represents the $24 \mathrm{~h}$ air temperature change

temperature rise since the previous day (colour code) was not outstanding, and snow cover was comparably thin (size of bubbles).

Figure 5 indicates a very strong sub-daily air temperature increase. In order to put that into perspective, we performed a temporally varying analysis of air temperature changes for the entire time series (2007-2016) where significant snow cover (SD >0.15) was present. Figure 9 shows the 1, 25, 50, 75 and 99 percentile (blue boxplot) for air temperature changes from 1 to $48 \mathrm{~h}$ (x-axis). Naturally, the range increases with increasing time span, i.e. the longer the interval studied, the more varying temperature rise can be. The red dots display the case of air temperature changes relative to the maximum measured air temperature that occurred prior to 11 April 2016, 09:00. They thus display to what extent the air temperature rise has been extraordinary in comparison with the general distribution. In terms of a short-term air temperature rise (between three and $7 \mathrm{~h}$ prior to the maximum), it has been the strongest on record. It was during this abrupt warming that we observed the highest precipitation rates (Fig. 5), which likely caused saturation and destabilization of the snowpack. We confine the connection to atmospheric drivers to the decade of comprehensive multi-disciplinary monitoring (2007-2016) since the evaluation of the time-lapse images is only possible there and the assessment whether other conditions led to similar events otherwise remains speculative.

Both the general synoptic conditions and the spatial precipitation patterns of 11 April 2016 strikingly resemble those of 19 selected events (marked in Fig. 8 with date and their composite map in Fig. S4a and c). Warm air masses transported along a pressure ridge towards Southwest Greenland are a consistent precondition for potential rain-onsnow events (i.e. snow cover present, strong precipitation during warm air temperatures) that can cause saturation of the snowpack and thus favour avalanche activity. In addition, in the 2016 case described, the winter snowpack was very thin $(<0.4 \mathrm{~m}$ in the low-land). Thin snowpacks are often rather unstable due to favourable conditions for 


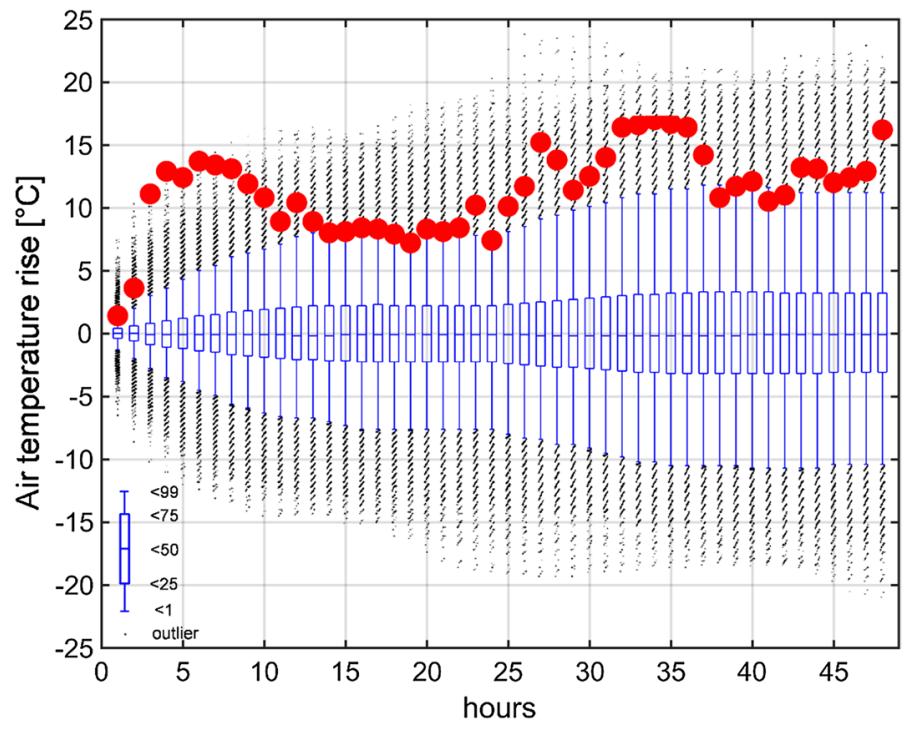

Fig. 9 Air temperature rise frequency: Boxplots of 1- to 48-h air temperature changes for the entire time series of Kobbefjord 2007-2016 when significant snow cover was present (snow depth $>0.15 \mathrm{~m}$ ). The blue bars represent the 1, 25, 50, 75 and 99 percentiles. Black markers indicate $<1$ and $>99$ percentiles. The red dots display the respective 1- to 48-h air temperature rise prior to the observed avalanche event on 11 April 2016, 9:00

the growth of faceted crystal or depth-hoar formation (e.g. Singh et al. 2011) and allow rapid saturation when melt and rain combine.

A rapid hydrological response was observed: Fig. 10 shows that the event presented in this study leads to the second highest discharge values on record, despite not extraordinary rain amounts and a thin snow cover.

Fig. 10 Discharge: Annual course of discharge from Bades $\emptyset$ measured at BS_Q: Black lines show the individual years since 2008, the red line the 2008-2016 average and the blue line 2016 . The April 2016 event is marked with a black arrow

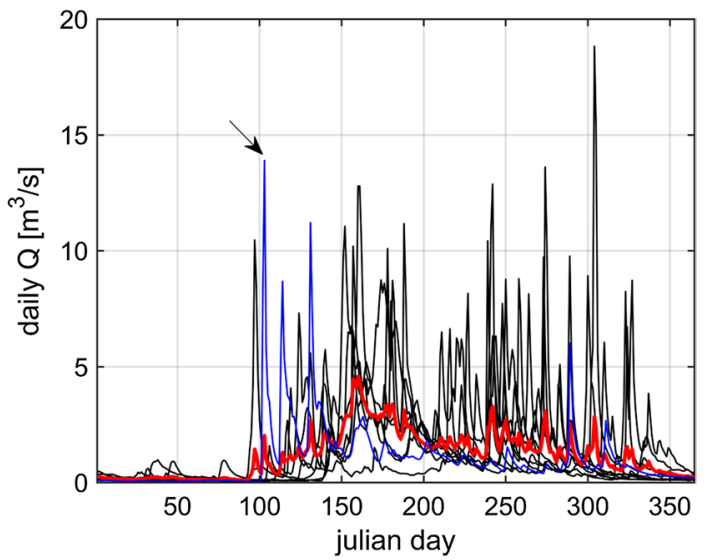




\section{Discussion}

\subsection{Radar satellite-borne avalanche detection: capabilities and limitations}

Quantification of the magnitude and spatial extent of extreme avalanche cycles is not possible with traditional field-based monitoring particularly in low-populated areas. Using radar satellite data provided by the Sentinel-1 constellation, avalanches can be detected anywhere globally, unaffected by light and cloud conditions (Eckerstorfer et al. 2016).

Avalanches exhibit a change in surface roughness that can be measured using microwave radar (Eckerstorfer and Malnes 2015). Since snow properties do change naturally throughout the snow season, avalanche quantification based on changes in surface properties is challenging. A relative backscatter difference between avalanche debris and surrounding undisturbed snow of $3.7 \mathrm{~dB}$ was previously used (Eckerstorfer and Malnes 2015). They then formulated a qualitative model of backscatter from dry and wet snow avalanche debris based on an earlier study (Ulaby et al. 1986). A fixed backscatter threshold (Vickers et al. 2016) was not usable in automatic detection, however, a dynamic one, adjusted to the snow conditions in the change detection image proofed successful, which is why we manually delineated avalanche debris in our study. Comparison with time-lapse imagery shows that we were able to identify individual features. Potential false detections occur when interpreting geomorphological features such as debris flow tracks as avalanche debris. The use of an activity map produced out of two Sentinel-1 scenes mitigates this problem largely as such geomorphological features exhibit no change within a short period of time. Another potential error source is the accurate delineation of the fuzzy transition between avalanche debris and slide path. While the aforementioned error sources do not influence the amount of detections, they certainly add uncertainty in the statistical analysis of avalanche sizes. This applies to identifying and delineating avalanche debris. Finally, the SAR sensors on board the Sentinel-1 satellites are side-looking instruments. This means that radar shadow and layover effects occur in mountainous areas, inducing areas without information. In our case, $98 \%$ of the landmass in the Sentinel-1 image was usable for detection. Overall, an underestimation of avalanche activity of unknown quantity can be assumed with this method (Eckerstorfer et al. 2017).

Detection of avalanches in optical satellite images is based on the recognition of variations in contrast induced by avalanche debris (Eckerstorfer et al. 2016). Without extracting spatial or spectral information from the Sentinel-2 image, avalanches were detectable due to their erosional work, adding to the avalanche activity dataset collected from the RGBIC. An error source could be the temporal gap of 15 days between Sentinel-2 image acquisition and event date. However, the meteorological record from KF does not indicate favourable conditions for additional avalanching during this time period (11-26 April 2016), which is why we deem this a minor issue.

\subsection{Impacts on natural and human systems}

Ecosystem impact of an extreme climate event in a snow-covered Arctic can be manifold and has been studied before (Pedersen et al. 2015; Bokhorst et al. 2016). Snow-cover changes impact both humans, terrestrial and marine fauna and flora (Bokhorst et al. 2016) as well as the hydrological cycle (Pedersen et al. 2015). Rain-on-snow events can impact ungulate population dramatically, and such events will increase in the future (Rennert et al. 2009). What 
makes the event presented in our study special is the combination of a very abrupt air temperature rise to extremely warm conditions along with strong precipitation, i.e. an extreme warming and a rain-on-snow event. During such an event, the sudden air temperature rise can lead to abrupt snow depletion that in turn can expose plants to freezing and make them vulnerable to frost damage.

Likewise, the sudden snow depletion can indirectly alter the gas flux balance of the following summer by reducing moisture availability during the greening season since the water stored in the snow cover disappears in a sudden event (Lund et al. 2014). Frozen ground plays an additional role since little infiltration in the ground can take place and the entire rain and in addition to the melted snow leaves the catchment rather instantaneously.

Future conditions will increase both air temperatures (Collins et al. 2013), precipitation amounts (Bintanja and Selten 2014) and the fraction of precipitation that falls as rain (Bintanja and Andry 2017). This evolution will increase the potential for such an event to occur, and hence the mentioned ecosystem consequences may occur in greater frequency and magnitude.

\subsection{The April 2016 event in the context of other large-scale avalanche cycles}

Large-scale avalanche cycles have been reported earlier. A major avalanche cycle in February 1986 was reported (Birkeland and Mock 2001) with severe avalanching in large parts of the Western United States from Washington to Colorado. Rather than to an exceptional snowpack built up throughout the winter, they attribute the February 1986 avalanching to a severe storm event that produced significant precipitation amounts, mainly in the form of snow. Major avalanche cycles in Iceland were correlated to the variability in the North Atlantic Oscillation inducing snow build-up in avalanche starting zones (Keylock 2003). A review of major avalanche cycles in Austria ranked based on fatalities found the winters of 1950/51 and 1953/1954 particularly devastating (Höller 2009). More information has been compiled on the avalanche cycle of February 1999 (Wilhelm et al. 2000; Rousselot et al. 2010). There were several fatalities in the Alps due to major snow during several consecutive storm events. Another major avalanche cycle from the French Alps that occurred in December 2008 is described and attributed to triggering meteorological factors by statistical methods (Eckert et al. 2011).

The reported large-scale events mentioned above were consequences of instabilities resulting from heavy snow fall. The avalanche cycle we report is in that sense particular with fresh snow not being a major triggering cause but rather the rapid warming of a generally shallow snow cover through strong rain. The resulting avalanches were mainly slushflows and other types of wet snow avalanches. Similar to the event described in this study, heavy rain caused two extreme mid-winter slush and wet slab avalanche events in Svalbard in 2010 and 2011 (Eckerstorfer and Christiansen 2011). These avalanches were triggered by extended periods of air temperatures above freezing in combination with strong rain of up to $35 \mathrm{~mm}$ w.e. Moreover, similar to our study, the authors were able to distinguish slushflows from wet snow avalanches, with slushflows occurring at more gentle terrain (Eckerstorfer and Christiansen 2011).

\section{Conclusions}

We showed that a large-scale wet snow avalanche and slushflow event was triggered by abrupt warming and heavy precipitation in April 2016 in Greenland. Field observations and multi-disciplinary monitoring helped to evaluate the performance of avalanche detection 
with high-resolution satellite imagery. We conclude that this is a powerful method in order to place point-wise observations in a larger spatio-temporal context and present relevant ecosystem consequences. Elaborating on those will be vital in order to improve our understanding of a changing Arctic. For a future study we propose the application of an algorithm to determine potential avalanche release areas as done in other areas (Bühler et al. 2018) and to use our dataset to evaluate its performance under Arctic conditions. Our study highlights the importance of multi-variate monitoring in order to collect the relevant in situ data when an extraordinary event occurs.

Acknowledgements Open access funding provided by University of Graz. The authors would like to acknowledge the ClimateBasis and the GeoBasis sub-programmes of the Greenland Ecosystem Monitoring Programme (www.g-e-m.dk). The Greenland Research Council is acknowledged as well as the ESA Project SnowPilot (ESA contract PEA No: 400108202) and the Norwegian Space Centre Project SatSkred (NRS contract NIT.20.15.5). Kirsty Langley, Dorthe Petersen and Kerstin K. Rasmussen are acknowledged for constructive comments and help with Figs. 5 and 9.

Author contributions JA conceived the study. JA and ME contributed equally on data analysis and manuscript writing. EM processed the SAR data while BH provided the time-lapse imagery. All authors commented on the manuscript.

\section{Compliance with ethical standards}

Conflict of interest The authors declare that they have no conflict of interest.

Open Access This article is distributed under the terms of the Creative Commons Attribution 4.0 International License (http://creativecommons.org/licenses/by/4.0/), which permits unrestricted use, distribution, and reproduction in any medium, provided you give appropriate credit to the original author(s) and the source, provide a link to the Creative Commons license, and indicate if changes were made.

\section{References}

Abermann J, Hansen B, Lund M et al (2017) Hotspots and key periods of Greenland climate change during the past six decades. Ambio 46:3-11. https://doi.org/10.1007/s13280-016-0861-y

Bellaire S, van Herwijnen A, Mitterer C, Schweizer J (2017) On forecasting wet-snow avalanche activity using simulated snow cover data. Cold Reg Sci Technol. https://doi.org/10.1016/j.coldregion s.2017.09.013

Bintanja R, Andry O (2017) Towards a rain-dominated Arctic. Nat Clim Change. https://doi.org/10.1038/ nclimate 3240

Bintanja R, Selten FM (2014) Future increases in Arctic precipitation linked to local evaporation and sea-ice retreat. Nature 509:479

Birkeland KW, Mock CJ (2001) The major snow avalanche cycle of february 1986 in the Western United States. Nat Hazards 24:75-95

Bokhorst SF, Bjerke JW, Tømmervik H et al (2009) Winter warming events damage sub-Arctic vegetation: consistent evidence from an experimental manipulation and a natural event. J Ecol 97:1408-1415. https://doi.org/10.1111/j.1365-2745.2009.01554.x

Bokhorst S, Pedersen SH, Brucker L et al (2016) Changing Arctic snow cover : A review of recent developments and assessment of future needs for observations, modelling, and impacts. Ambio 2011:516-537. https://doi.org/10.1007/s13280-016-0770-0

Bühler Y, von Rickenbach D, Stoffel A et al (2018) Automated snow avalanche release area delineation validation of existing algorithms and proposition of a new object-based approach for large scale hazard indication mapping. Nat Hazards Earth Syst Sci Discuss. https://doi.org/10.5194/nhess-2018-124

Christensen TR, Topp-Jorgensen E (2018) Greenland ecosystem monitoring annual report cards 2017. DCE_-Danish Centre for Environment and Energy, Aarhus University, p 44 
Collins M, Knutti R, Arblaster J et al (2013) The physical science basis. IPCC working group I contribution to AR5. In: Stocker T (ed) The physical science basis. IPCC working group I contribution to AR5. Cambridge University Press, Cambridge

Cooper EJ (2014) Warmer shorter winters disrupt arctic terrestrial ecosystems. Annu Rev Ecol Evol Syst 45:271-295. https://doi.org/10.1146/annurev-ecolsys-120213-091620

Decaulne A, Sæmundsson T (2006) Meteorological conditions during slushflow release and their geomorphological impact in Nothwestern Iceland: a case study from the Bíldudalur valley. Geogr Ann 88A:187-197

Eckerstorfer M, Christiansen HH (2011) Meteorology, topography and snowpack conditions causing two extreme mid-winter slush and wet slab avalanche periods in high arctic maritime svalbard. Permafr Periglac Process. https://doi.org/10.1002/ppp.734

Eckerstorfer M, Malnes E (2015) Manual detection of snow avalanche debris using high-resolution Radarsat-2 SAR images. Cold Reg Sci Technol 120:205-218. https://doi.org/10.1016/J.COLDR EGIONS.2015.08.016

Eckerstorfer M, Bühler Y, Frauenfelder R, Malnes E (2016) Remote sensing of snow avalanches : recent advances, potential, and limitations. Cold Reg Sci Technol 121:126-140. https://doi.org/10.1016/j. coldregions.2015.11.001

Eckerstorfer M, Malnes E, Müller K (2017) A complete snow avalanche activity record from a Norwegian forecasting region using Sentinel-1 satellite-radar data. Cold Reg Sci Technol 144:39-51. https://doi.org/10.1016/j.coldregions.2017.08.004

Eckert N, Gaume J, Castebrunet H (2011) Using spatial and spatial-extreme statistics to characterize snow avalanche cycles. Procedia Environ Sci 7:224-229. https://doi.org/10.1016/j.proen v.2011.07.039

Fierz C, Armstrong RL, Durand Y, et al (2009) The international classification for seasonal snow on the ground. IHP-VII Technical Document in Hydrology 91

Furdada G, Martínez P, Oller P, Vilaplana JM (1999) Slushflows at El Port del Comte, northeast Spain. J Glaciol 45:555-558. https://doi.org/10.3189/S0022143000001428

Gude M, Scherer D (1995) Snowmelt and slush torrents-Preliminary report from a field campaign in Kärkevagge, Swedish Lappland. Geogr Ann Ser A Phys Geogr 77:199-206. https://doi. org/10.1080/04353676.1995.11880440

Hanna E, Mernild SH, Cappelen J, Steffen K (2012) Recent warming in Greenland in a long-term instrumental (1881-2012) climatic context: I. Evaluation of surface air temperature records. Environ Res Lett 7:045404. https://doi.org/10.1088/1748-9326/7/4/045404

Hansen BB, Isaksen K, Benestad RE et al (2014) Warmer and wetter winters: characteristics and implications of an extreme weather event in the High Arctic. Environ Res Lett 9:114021. https://doi. org/10.1088/1748-9326/9/11/114021

Hestnes E (1998) Slushflow hazard-where, why and when? 25 years of experience with slushflow consulting and research. Ann Glaciol 26:370-376

Hestnes E, Bakkehøi S (2004) Slushflow hazard prediction and warning. Ann Glaciol 38:45-51. https:// doi.org/10.3189/172756404781814889

Höller P (2009) Avalanche cycles in Austria: an analysis of the major events in the last 50 years. Nat Hazards 48(3):399-424. https://doi.org/10.1007/s11069-008-9271-1

Iversen KM, Pernosky (2010) Climate basis monitoring program Nuuk Basic, 2009. Asiaq-Greenland Survey, p 36. Asiaq Report no. 2010-04

Kalnay E, Kanamitsu M, Kistler R et al (1996) The NCEP/NCAR 40-year reanalysis project. Bull Am Meteorol Soc 77:437-471. https://doi.org/10.1175/1520-0477(1996)077

Keylock CJ (2003) The North Atlantic Oscillation and snow avalanching in Iceland. Geophys Res Lett 30:1254. https://doi.org/10.1029/2002g1016272

Larsen Y, Engen G, Lauknes TR et al (2005) A generic differential interferometric SAR processing system, with applications to land subsidence and snow-water equivalent retrieval. Fringe ATSR Work 2005:6

Larsen SØ, Salberg A, Solberg R (2013) Automatic avalanche mapping using texture classification of optical satellite imagery. In: EARSeL eProceedings, pp 399-410

Lato MJ, Frauenfelder R, Bühler Y (2012) Automated detection of snow avalanche deposits: segmentation and classification of optical remote sensing imagery. Nat Hazards Earth Syst Sci 12:28932906. https://doi.org/10.5194/nhess-12-2893-2012

Lu D, Mausel P, Brondízio E, Moran E (2004) Change detection techniques. Int J Remote Sens 25:23652401. https://doi.org/10.1080/0143116031000139863

Lund M, Hansen BU, Pedersen SH et al (2014) Characteristics of summer-time energy exchange in a high Arctic tundra heath 2000 2010. Tellus B 66:1-14. https://doi.org/10.3402/tellusb.v66.21631

McClung DM, Schaerer P (2006) The avalanche handbook, 3rd edn. The Mountaineers Books, Seattle 
Mitterer C, Schweizer J (2013) Analysis of the snow-atmosphere energy balance during wet-snow instabilities and implications for avalanche prediction. Cryosph 7:205-216. https://doi.org/10.5194/ tcd-6-2715-2012

Nagler T, Rott H (2000) Retrieval of wet snow by means of multitemporal SAR data. IEEE Trans Geosci Remote Sens 38:754-765. https://doi.org/10.1109/36.842004

Nobles LH (1966) Slush avalanches in Northern Greenland and the classification of rapid mass movements. Ass Int Hydrol Sci Publ 69:267-272

Onesti L (1985) Meteorological conditions that initiate slushflows in the Central Brooks Range, Alaska. Ann Glaciol 6:23-25

Pedersen SH, Liston GE, Tamstorf MP et al (2015) Quantifying episodic snowmelt events in arctic ecosystems. Ecosystems 18:839-856. https://doi.org/10.1007/s10021-015-9867-8

Rapp A (1960) Recent development of mountain slopes in Kärkevagge and surroundings, Northern Scandinavia. Geogr Ann 42:65-200. https://doi.org/10.1080/20014422.1960.11880942

Rennert KJ, Roe G, Putkonen J, Bitz CM (2009) Soil thermal and ecological impacts of rain on snow events in the circumpolar arctic. J Clim 22:2302-2315. https://doi.org/10.1175/2008JCLI2117.1

Rogers JC, Hellstrom RA, Mosley-Thompson E, Wang CC (1997) An abrupt spring air temperature rise over the Greenland ice cap. J Geophys Res 102:13793-13800

Rousselot M, Durand Y, Giraud G et al (2010) Analysis and forecast of extreme new-snow avalanches: a numerical study of the avalanche cycles of February 1999 in France. J Glaciol 56:758-770

Rudolf-Miklau F, Sauermoser S, Mears AI (2015) The technical avalanche protection handbook, 1st edn. Wiley, Ernst und Sohn, Hoboken

Singh VP, Vijay P, Haritashya UK (2011) Encyclopedia of snow, ice and glaciers. Springer Netherlands, Amsterdam

Ulaby FT, Moore RK, Fung AK (1986) Microwave remote sensing: active and passive; from theory to applications. Artech House, Norwood

Vickers H, Eckerstorfer M, Malnes E et al (2016) A method for automated snow avalanche debris detection through use of synthetic aperture radar (SAR) imaging. Earth Space Sci 3:446-462. https://doi. org/10.1002/2016EA000168

Vikhamar-Schuler D, Isaksen K, Haugen JE et al (2016) Changes in winter warming events in the nordic arctic region. J Clim 29:6223-6244. https://doi.org/10.1175/JCLI-D-15-0763.1

Walsh JE, Overland JE, Groisman PY, Rudolf B (2012) Ongoing climate change in the arctic. Ambio 40:616. https://doi.org/10.1007/s13280-011-0211-z

Washburn L, Goldthwait RP (1958) Slushflows. Bull Geol Soc Am 69:1657-1658

Wiesmann A, Wegmuller U, Honikel M, et al (2001) Potential and methodology of satellite based SAR for hazard mapping. In: IGARSS 2001. Scanning the Present and Resolving the Future. Proceedings. IEEE 2001 international geoscience and remote sensing symposium (Cat. No.01CH37217), vol 7, pp 3262-3264

Wilhelm C, Wiesinger T, Bründl M, Ammann W (2000) The avalanche winter 1999 in Switzerland-an overview. In: Proceedings of 2000 international snow science workshop, pp 487-494

Publisher's Note Springer Nature remains neutral with regard to jurisdictional claims in published maps and institutional affiliations. 